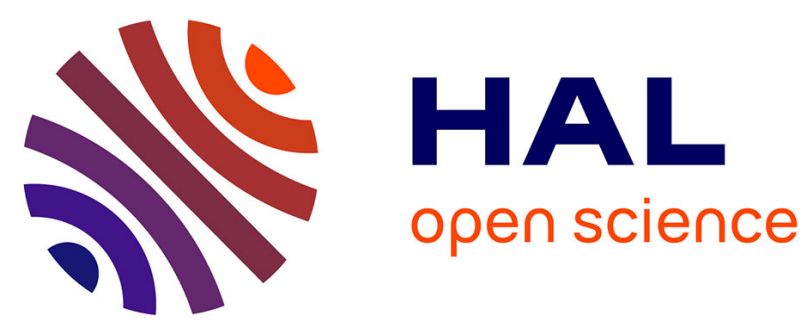

\title{
D. - LIQUIDS.AN INTRODUCTION TO THE STUDY OF LIQUID METALS AND ALLOYS
}

\author{
J. Enderby
}

\section{To cite this version:}

J. Enderby. D. - LIQUIDS.AN INTRODUCTION TO THE STUDY OF LIQUID METALS AND ALLOYS. Journal de Physique Colloques, 1974, 35 (C4), pp.C4-309-C4-312. 10.1051/jphyscol:1974459 . jpa-00215650

\section{HAL Id: jpa-00215650 https://hal.science/jpa-00215650}

Submitted on 1 Jan 1974

HAL is a multi-disciplinary open access archive for the deposit and dissemination of scientific research documents, whether they are published or not. The documents may come from teaching and research institutions in France or abroad, or from public or private research centers.
L'archive ouverte pluridisciplinaire HAL, est destinée au dépôt et à la diffusion de documents scientifiques de niveau recherche, publiés ou non, émanant des établissements d'enseignement et de recherche français ou étrangers, des laboratoires publics ou privés. 


\title{
AN INTRODUCTION TO THE STUDY OF LIQUID METALS AND ALLOYS
}

\author{
J. E. ENDERBY
}

\author{
Department of Physics \\ University of Leicester \\ England
}

\begin{abstract}
Résumé. - On présente une courte revue des propriétés électriques des métaux et des alliages liquides en se référant particulièrement aux alliages à base d'un métal alcalin et aux alcalins terreux liquides. Puis on se concentre sur des problèmes structuraux associés à des alliages liquides, particulièrement ceux dans lesquels une transition métal-semiconducteur se produit graduellement lorsque la composition change. Des résultats expérimentaux sont confrontés à des modèles structuraux qui impliquent la notion d'amas. On proposera un rapport explicite entre les propriétés structurales d'une part et les propriétés électroniques d'autre part.

Abstract. - A brief review is given of the electrical properties of liquid metals and alloys with special reference to alkali metal based alloys and the liquid alkaline earths. Attention is then focussed on structural problems associated with liquid alloys particularly those in which a gradual transition occurs from metallic to semiconducting behaviour as the composition is varied. Experimental evidence will be presented against structural models which involve the notion of clusters. An explicit connection between the structural properties on the one hand and the electronic properties on the other will be suggested.
\end{abstract}

1. The electrical properties of pure liquid metals. 1.1 Simple Liquid METALS. - The theoretical and experimental situation for simple liquid metals (i. e. those in which $d$ - or f-like resonance behaviour is well removed from the Fermi energy $E_{\mathrm{F}}$ ) has not materially changed since the review article by Cusack [1] was written a decade ago. Tentative generalisations made at that time have, with the passage of time, become generally accepted. The nearly free electron picture of liquid metals as evidenced by Hall coefficient, electrical resistivity and optical studies, is now well established and for an up-to-date review of the present situation the reader is referred to the book by Faber [2]. The Ziman [3] formula for the electrical resistivity, involving as it does the pseudopotential and the liquid structure factor, has received considerable experimental support in recent years.

1.2 LIQUid ALKaLINE EARTH METALS. - The group Ila elements $(\mathrm{Mg}, \mathrm{Ca}, \mathrm{Sr}$ and $\mathrm{Ba}$ ) are important because they represent, in the condensed states, metals which are precursors of the transition series. The effect of the empty d-states above $E_{\mathrm{F}}$ will therefore begin to affect the electrical properties and to this end a study of the resistivity and thermoelectric power of liquid alkaline earth metals has now been completed (Van Zytveld, Enderby and Collings [4]). The resistivity measurements were interpreted in terms of resonance scattering from the vacant d-states. The thermoelectric power results indicated the increasing role of the energy dependence of the pseudopotential as one proceeds from $\mathrm{Mg}$ to $\mathrm{Ba}$. Calculations by Ratti and Evans [5] in which the effect of the d-bands is incorporated into an energy dependent pseudopotential confirm this trend.

2. The electrical properties of liquid alloys. - In 1964 Faber and Ziman [6] showed that if scattering of electrons in a binary alloy is treated in Born approximation, the resistivity can again be evaluated in terms of pseudopotentials and structure factors.

Let us define a generalised form factor $F(q)$ given by :

$$
\begin{aligned}
F(q)=\left|w_{1}\right|^{2} & {\left[c(1-c)+c^{2} a_{11}\right]+} \\
& +\left|w_{2}\right|^{2}\left[c(1-c)+(1-c)^{2} a_{22}\right] \\
& +2 w_{1} w_{2} c(1-c)\left(a_{12}-1\right) .
\end{aligned}
$$

Here the pseudopotentials of the two components are written as $w_{1}$ and $w_{2}$, while $c$ is the atomic fraction of component $1 ; a_{11}, a_{22}$ and $a_{12}$ represent the three partial structure factors, the definition and determination of which will be discussed in paragraph 3 . It then follows that the conductivity $\sigma$ of a binary liquid alloy can be expressed as

$$
\sigma=\left\{\frac{3 \pi^{2}}{e^{2} \hbar v_{F}^{2}} \Omega<F(q)>\right\}^{-1}
$$


where

$$
\langle F\rangle=\int_{0}^{2 k_{F}} F(q) q^{3} \mathrm{~d} q
$$

$v_{F}$ and $k_{F}$ are respectively the Fermi velocity and Fermi wave number and $\Omega$ is the atomic volume.

A thoroughgoing comparison of theory and experiment is not in general possible because information about the partial structure factors $a_{\alpha \beta}$ is limited. However when $a_{\alpha \beta}$ can be plausibly assumed to be independent of $c$ (e. g., liquid $\mathrm{Au}-\mathrm{Ag}$ ) or determined directly (e. g. liquid $\mathrm{Cu}-\mathrm{Sn}$ ) the experimental transport data for a certain class of liquid alloys are in excellent agreement with those predicted by the Faber-Ziman theory. Such alloys are characterised by conductivities greater than $\sim 3000 \Omega^{-1} \mathrm{~cm}^{-1}$, thermopowers $(S)$ less than $\pm 50 \mu \mathrm{Vdeg}^{-1}$, and Hall coefficients $(R)$ which are not significantly different from $R_{0}$, the free electron value. This type of liquid has been called a Type I alloy by Enderby and Collings [7] and includes a range of systems, e. g. (Bi-Te, $\mathrm{Au}-\mathrm{Te}, \mathrm{Cd}-\mathrm{Sb}$ ) which were once considered to be semiconducting in character (Joffe and Regel [8]).

There exists a second group of liquid alloys (Type II in the notation of Enderby and Collings) whose electronic properties are different from those of metallic (i. e. Faber-Ziman) systems and are rather similar to those of semiconductors. Such liquids are usually referred to as «liquid semiconductors». Two main types of liquid semiconductors have been identified, namely, those based on the chalcogenides (for example, liquid $\mathrm{Cu}_{2} \mathrm{Te}$ ) and those in which metals of vastly different electronegativities are alloyed together. These latter systems are of considerable interest because they enable the experimenter to follow continually the transition from metallic behaviour to semiconducting behaviour. Liquid $\mathrm{Mg}-\mathrm{Bi}$ and $\mathrm{Mg}-\mathrm{Sb}$ represent two of the alloys which are known to fall into this group. Experimental results for $\sigma$ and $S$ have been reported for liquid $\mathrm{Mg}-\mathrm{Bi}$ by Ilschner and Wagner [9] and by Enderby and Collings [7]. At the composition $\mathrm{Mg}_{3} \mathrm{Bi}_{2}$, the minimum value in $\sigma$ is associated with a sign change in $S$ and a positive $\mathrm{d} \sigma / \mathrm{d} T$. It is clear from this evidence and from the behaviour of the excess free energy that a major change in the bonding characteristics takes place as we proceed from pure liquid $\mathrm{Bi}$ or $\mathrm{Mg}$ to the liquid alloy $\mathrm{Mg}_{3} \mathrm{Bi}_{2}$.

Some recent experiments on alkali metal based type II liquid alloys have been completed in our laboratory at Leicester. Results for $S$ and $\sigma$ for one of them (Li-Pb) due to Nguyen (private communication) are shown in figures 1 and 2 . These results suggest that the dip in the conductivity coupled with a sign change in the thermopower is associated with a chemical valence effect and is not a direct consequence of the existence of a solid state compound. (There are four intermetallic compounds in the solid

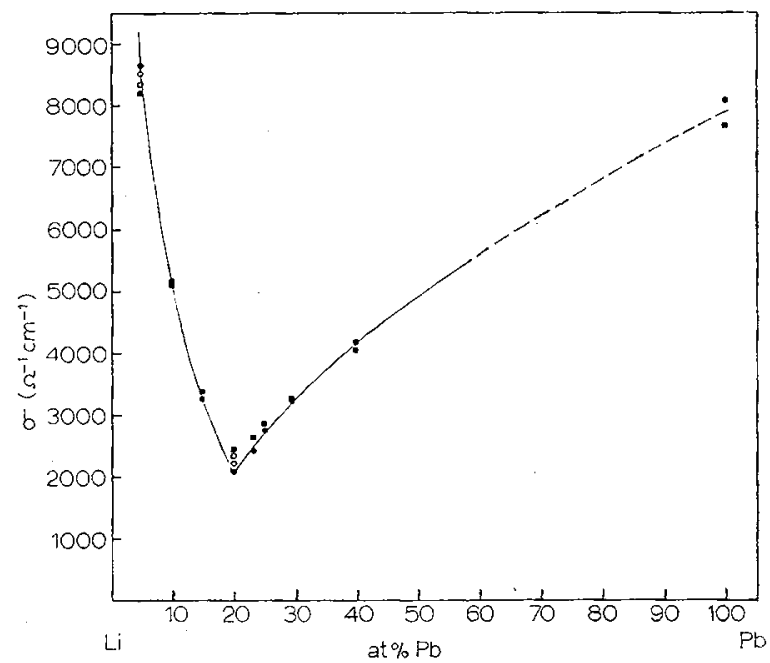

Frg. 1. - The electrical conductivity of liquid Li-Pb

- $800^{\circ} \mathrm{C} \quad \bigcirc \quad 850^{\circ} \mathrm{C} \square 900^{\circ} \mathrm{C} \square 950^{\circ} \mathrm{C}$.

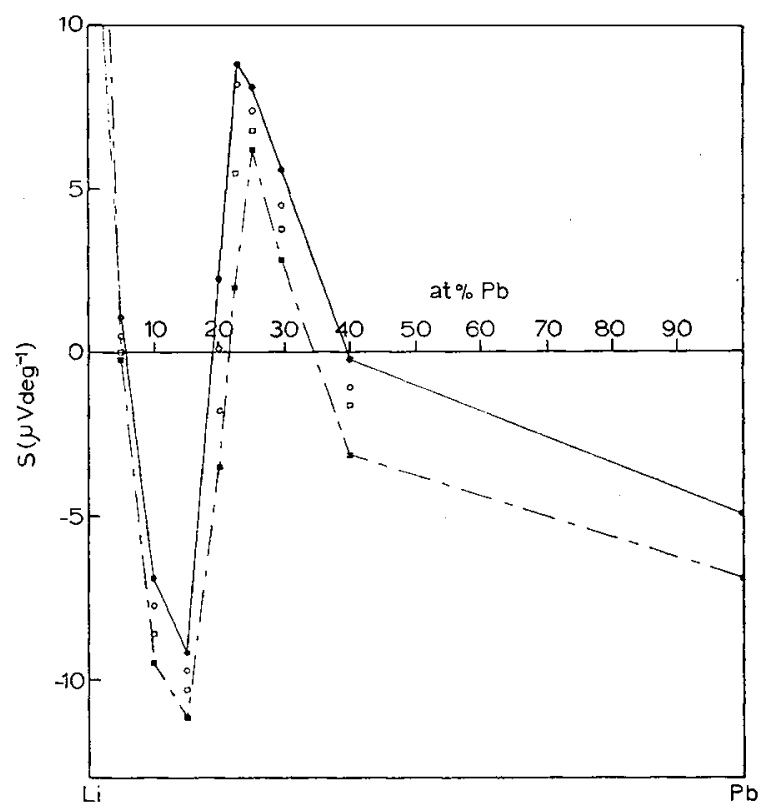

Frg. 2. - The absolute thermoelectric power of liquid $\mathrm{Li}-\mathrm{Pb}$

- $800^{\circ} \mathrm{C} \bigcirc 850^{\circ} \mathrm{C} \square 900^{\circ} \mathrm{C} \square 950^{\circ} \mathrm{C}$.

state but the anomaly occurs only at the composition $\mathrm{Li}_{4} \mathrm{~Pb}$.)

Our basic understanding of these liquids is still in a very primitive state ; the development of a comprehensive theoretical treatment in which the various electronic and thermodynamic properties of liquid semiconductors can be discussed, has been hampered by the lack of information about the nature of the atomic order which exists in alloys of this type. We therefore turn, in this introductory account of liquid metal physics, to problems associated with the structure of binary liquid alloys. 
3. The structure of liquid alloys. - 3.1 PARTIAL STRUCTURE FACTORS. - We define a partial structure factor, $a_{\alpha \beta}$, through

$$
a_{\alpha \beta}(q)=1+\frac{4 \pi n}{q} \int \mathrm{d} r\left[g_{\alpha \beta}(r)-1\right] r \sin q r
$$

where $g_{\alpha \beta}$ represents the distribution of type $\alpha$-atoms observed from a $\beta$-atom at the origin, $n$ is the number density of atoms irrespective of type, $q$ is the conventional momentum transfer variable, and $\alpha$ and $\beta$ are dummy suffices which take on the values 1 and 2 for a binary alloy. In terms of the differential scattering cross-section, a quantity which can be determined experimentally, it can be readily shown that

$$
\frac{\mathrm{d} \sigma}{\mathrm{d} \Omega}=c_{1} f_{1}^{2}+c_{2} f_{2}^{2}+F(q) .
$$

Here $c_{1}$ and $c_{2}$ are the atomic concentration of two constituents, $f_{1}$ and $f_{2}$ the appropriate scattering factors and $F(q)$ is given by

$$
\begin{aligned}
F(q)=c_{1}^{2} f_{1}^{2}\left(a_{11}-1\right)+c_{2}^{2} & f_{2}^{2}\left(a_{22}-1\right)+ \\
& +2 c_{1} c_{2} f_{1} f_{2}\left(a_{12}-1\right) .
\end{aligned}
$$

Thus, in order to discuss liquid alloys from a fundamental standpoint, three partial structure factors $a_{11}$, $a_{12}$ and $a_{22}$ are required. To obtain these, three separate determinations of $\mathrm{d} \sigma / \mathrm{d} \Omega$ for the same alloy must be made by changing $f_{1}$ or $f_{2}$. It is now clear that the only feasible means of carrying out such experiments is to combine neutron diffraction methods with the use of isotopically enriched samples (Enderby, North and Egelstaff [10]).

As part of a continuing programme (see, for instance, Enderby et al. [10], Enderby and Howells [11]) designed to lead to a fuller understanding of the structure of liquid alloys, Hawker, Howe and Enderby [12] have recently completed measurements on liquid $\mathrm{CuTe}$ and liquid $\mathrm{Cu}_{2} \mathrm{Te}$. Three samples of $\mathrm{CuTe}$ and $\mathrm{Cu}_{2} \mathrm{Te}$ were prepared using natural $\mathrm{Te}$ and (i) natural copper, (ii) copper enriched to $99 \%$ with ${ }^{63} \mathrm{Cu}$, (iii) copper enriched to $99 \%$ with ${ }^{65} \mathrm{Cu}$. The coherent scattering cross-sections for ${ }^{n a t} \mathrm{Cu},{ }^{63} \mathrm{Cu}$, ${ }^{65} \mathrm{Cu}$ and $\mathrm{Te}$ are in the proportion 1:0.73: $1.96: 0.51$.

Several conclusions have emerged from this study, the most significant being that the existence of clusters in semiconducting alloys of the $\mathrm{Cu}$-Te type has not been confirmed. Such clusters were first postulated by Hodgkinson [13] and by Cohen and Sak [14] as a basis for a general discussion of the electrical properties of liquid semiconductors.

The partial structure factors for liquid $\mathrm{Cu}_{2} \mathrm{Te}$ are displayed in figure 3 , the vertical lines indicating the residual uncertainty due to the inevitable experimental errors in $F(q)$. Hawker et al. have drawn attention to three features which they consider to be worthy of special note :

a) the similarity between $a_{\mathrm{CnCu}}$ and the structure factor for pure liquid copper;

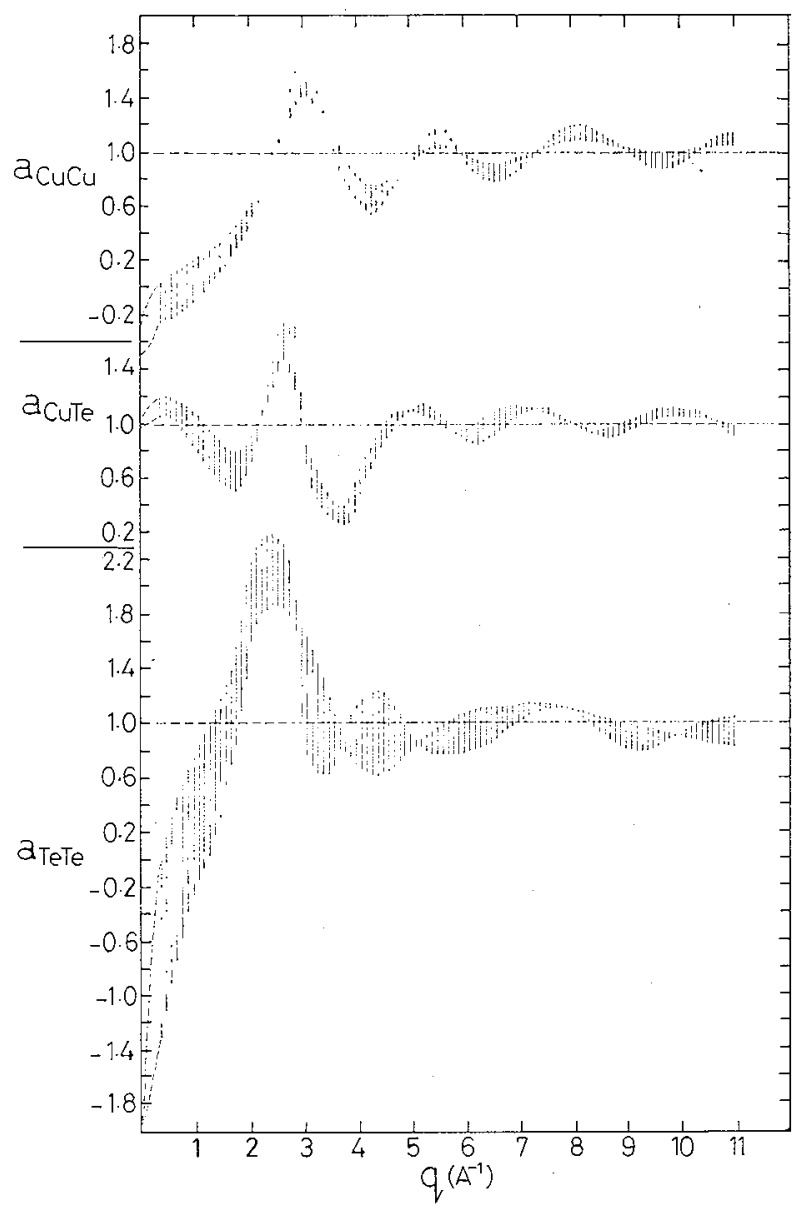

FIG. 3. - The partial structure factors for liquid $\mathrm{Cu}_{2} \mathrm{Te}$ at $1000^{\circ} \mathrm{C}$.

b) the significant difference between $a_{\mathrm{TeTe}}$ and the structure factor for pure liquid $\mathrm{Te}$;

c) the absence of a definite feature in any of the partial structure factors corresponding to a «prepeak » which was found in $F(q)$ at a $q$ value of $1 \mathrm{~A}^{-1}$.

The first feature suggests that the packing of the $\mathrm{Cu}$ ions in liquid $\mathrm{Cu}_{2} \mathrm{Te}$ is a highly disordered one dominated by a hard-core interaction equal to that for $\mathrm{Cu}$ ions in pure liquid $\mathrm{Cu}$, whilst the second one indicates that the covalent character of pure liquid Te disappears as $\mathrm{Cu}$ is added. These conclusions are consistent with the view expressed by Enderby and Hawker [15] that models involving $\mathrm{Cu}$ substitutions into covalent Te chains are unlikely to be useful as a starting point for explaining the properties of liquid $\mathrm{Cu}-\mathrm{Te}$ alloys. The third feature illustrates very clearly the danger in attempting to relate maxima in $F(q)$, particularly at low $q$, to a particular distance in real space. The pre-peak in $F(q)$ simply reflects the effect of combining three partial structure factors each with a characteristic $q$-dependence. Hawker et al. found no evidence of long range order in any of partial radial distribution functions.

The extent to which the measured partial structure factors are consistent with a more or less random 


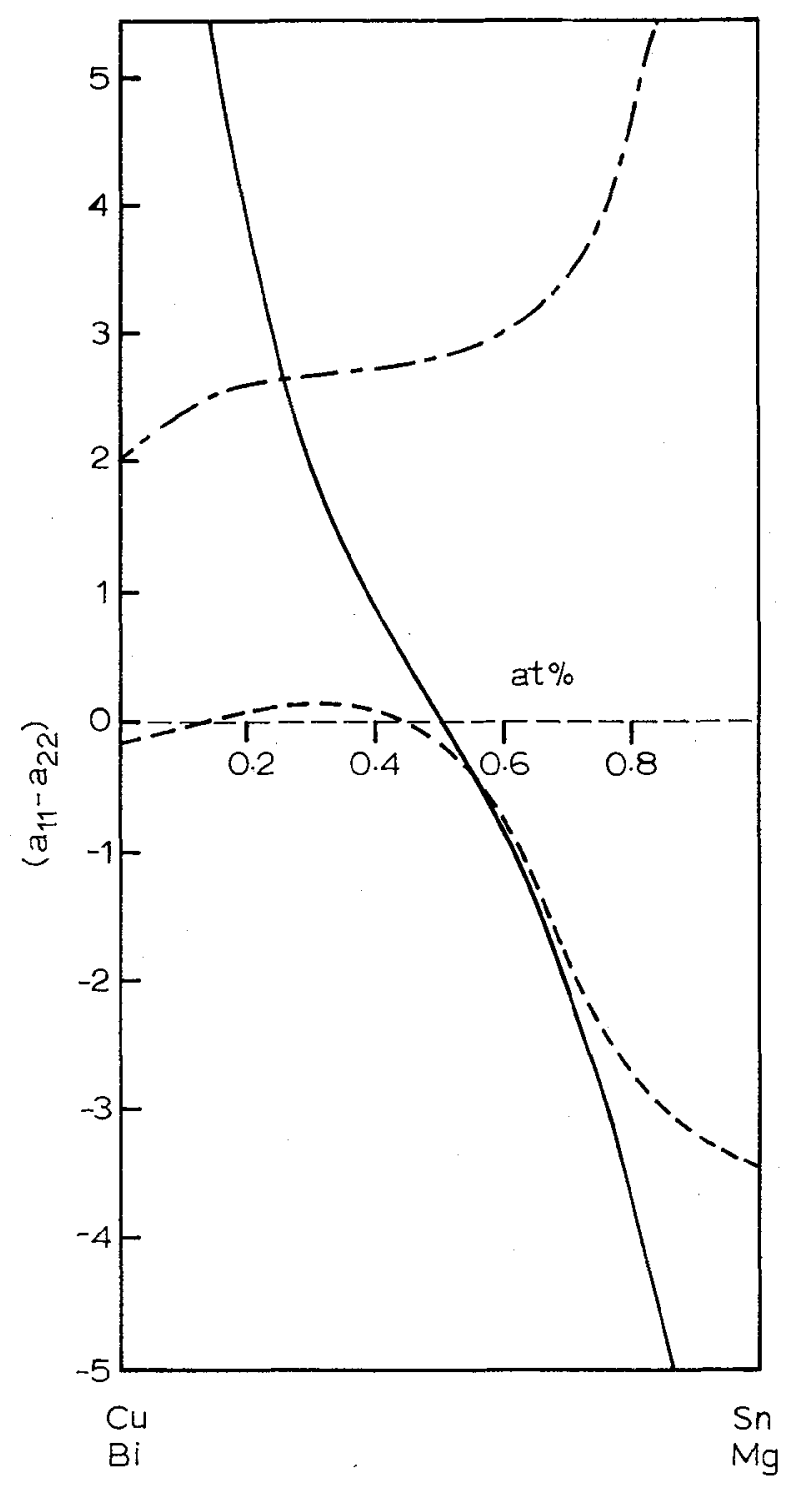

FIG. 4. $-a_{11}-a_{22}$ as a function of composition

-.-.-.-. - liquid $\mathrm{Cu}-\mathrm{Sn}$

$\ldots-\ldots-\ldots--$ liquid $\mathrm{Mg}-\mathrm{Bi}$

$\left(1 / c_{1}-1 / c_{2}\right)$.

mixture of $\mathrm{Cu}$ and $\mathrm{Te}$ ions in which substantial electron transfer has taken place is currently under theoretical investigation by the Leicester Group. So far, this kind of model looks to be the most promising although considerably more numerical work will have to be undertaken before definitive conclusions can be reached.

3.2 THE LONG-WaVe LIMIT OF THE PARTIAL STRUCTURE FACTORS. - If we suppose that Type II alloys at the stoichiometric composition are essentially ionic in character, and that all the electrons are localized on ion sites, the Stillinger-Lovett [16] condition for electrical neutrality implies that

$$
a_{11}(0)-a_{22}(0)=\frac{1}{c_{1}}-\frac{1}{c_{2}} .
$$

Recently, the thermodynamic relationship for $a_{\alpha \beta}(0)$ derived by McAlister and Turner [17] have been applied to liquid Cu-Sn (a type I alloy) by Turner, Crozier and Cochran (*) and to liquid Mg-Bi (a type II alloy) by McAlister, Crozier and Cochran [18]. In figure 4 a comparison between $a_{11}-a_{22}$ and $\left(\frac{1}{c_{1}}-\frac{1}{c_{2}}\right)$ is made for both systems. The «ionic » curve fits the data only for the type II system in the region around $\mathrm{Mg}_{3} \mathrm{Bi}_{2}$ indicating that the electrical neutrality condition can be met over a range of composition almost entirely by considering the ionic structure factors alone. This strongly suggests that a gap (or pseudo gap) in the electron energy spectrum must have developed around the stoichiometric composition. A sufficient condition for

$$
\left(a_{11}-a_{22}\right)=\left(\frac{1}{c_{1}}-\frac{1}{c_{2}}\right)
$$

is that $\partial^{2} G / \partial c_{2}^{2}=\infty$ where $G$ is the Gibbs free energy. Interestingly, Darken [19] has defined $\partial^{2} G / \partial c_{2}^{2}$ as a «stability function » and finds that it exhibits large peaks at stoichiometric compositions which he empirically relates to valence considerations or the existence of solid state compounds.

(*) Private communication.

\section{References}

[1] CuSACK, N., Rep. Prog. Phys. 26 (1963) 361.

[2] FABER, T. E., Introduction to the Theory of Liquid Metals (Cambridge University Press) 1972.

[3] Ziman, J. M., Phil. Mag. 6 (1961) 1013.

[4] VAN ZyTVeldT, J. B., ENDERBY, J. E. and Collings, E. W., J. Phys. F 2 (1972) 73.

VAn Zytveldt, J. B., Enderby, J. E. and Collings, E. W., J. Phys. F 3 (1973) 1819.

[5] Ratti, V. K. and Evans, R., J. Phys. F 3 (1973) L238.

[6] Faber, T. E. and Ziman, J. M., Phil. Mag. 11 (1964) 153.

[7] Enderby, J. E. and Collings, E. W., J. Non-Cryst. Solids 4 (1970) 161.

[8] Joffe, A. F. and Regel, A. R., Progress in Semiconductors (ed. A. F. Gibson, Wiley, New York) 1960.

[9] ILSCHNER, B. R. and WAGNER, C. N., Acta Met. 6 (1965) 712.

[10] Enderby, J. E., North, D. M. and Egelstaff, P. A., Phil. Mag. 14 (1966) 453.

[11] Enderby, J. E. and Howells, W. S., in Interatomic Poten- tials and Simulation of Lattice Defects (ed. P. C. Gehlen et al.), p. 217, Plenum, New York.

[12] Hawker, I., Howe, R. A. and ENDERBy, J. E., Proceedings of the 5th Int. Conference on Liquid and Amorphous Semiconductors (to be published).

[13] Hodgkinson, R. J., Phil. Mag., 22 (1970) 1187.

[14] Cohen, M. H. and SAK, J., J. Non-Cryst. Solids 8-10 (1972) 696.

[15] Enderby, J. E. and HAwker, I., J. Non-Cryst. Solids 8-10 (1972) 687.

[16] Stillinger, F. H. and Lovett, R, J. Chem. Phys. 49 (1968) 1991.

[17] MCAlister, S. P. and Turner, R., J. Phys. F 2 (1972) L51.

[18] McAlister, S. P., Crozier, E. D. and Cochran, J. F., Proceedings of the 2 nd Int. Conf. on the Properties of Liquid Metals (ed. S. Takeuchi), p. 445 (1973).

[19] Darken, L. S., Trans. AIME 239 (1967) 80. 